\title{
Modified Waste Materials for Removal of Cationic Dye from Liquid Effluents and Their Kinetic Studies
}

\author{
O.G. Allam, N.A. Fathy ${ }^{*}$, M. G. Khafagj ${ }^{* *}$ and M.K. El-Bisi \\ Textile Research Division, ${ }^{*}$ Inorganic Chemical Industries \\ Division and ${ }^{* *}$ Physics Division,National Research Centre, \\ Dokki, Giza, Egypt.
}

\begin{abstract}
T $\mathrm{N}$ the present paper, natural adsorbents such as starch, 1 sawdust (collected from a local sawmill) and orange peel were grafted in order to remove C.I. Basic Blue 41 (BB 41) from aqueous solution by adsorption. Batch mode experiments were conducted at $30^{\circ} \mathrm{C}$ to study the effects of $\mathrm{pH}$, adsorbent mass and contact time $(0-$ $240 \mathrm{~min})$. Equilibrium adsorption isotherms and kinetics were investigated. The experimental adsorption data were analyzed by the Langmuir and Freundlich isotherms. The results showed that adsorption capacity is dependent on the $\mathrm{pH}$, initial concentration of dye and contact time. Changes in the surface chemical groups in the adsorbent starch, orange peel and sawdust waste materials were investigated via Fourier transform infrared (FTIR). In the case of starch and sawdust the $\mathrm{OH}$ group after grafting is reduced while the carboxylic group is increased and vice versa after adsorption of a dye, indicating that the adsorption of dye is occurred between carboxylic groups and cationic group in basic dye. But in the case of orange peel the result is conversely. Equilibrium isotherms were well described by the Langmuir equation, giving maximum adsorption capacity of 19.2 $\mathrm{mg} / \mathrm{g}$ by sawdust adsorbent at $30^{\circ} \mathrm{C}$. The adsorption kinetics can be well represented by the pseudo-second-order model equation.
\end{abstract}

Keywords: Starch, Orange peel and sawdust, Basic blue, Adsorption isotherm, Equilibrium and Kinetics.

The removal of dye from textile effluents is one of the most significant environmental problems. Dyes are used widely in modern industrial society. Since they have a synthetic origin and complex aromatic molecular structures which make them inert and difficult to biodegrade when discharged into waste streams. Also, many dyes and their break down products may be toxic for living organism. So, the removal of dyes and organics from water in an economical way remains an important problem. There is no general method for the removal of color from dye wastewater ${ }^{(1,2)}$. Many treatment methods have been adopted to remove dyes from wastewater, which can be divided into physical, chemical, and biological methods ${ }^{(3)}$. Processes such as membrane separation, coagulation and ion exchange are also used for the removal of color from dye waste water, but the cost of the process is the main drawback of these techniques ${ }^{(4)}$. A number of non-conventional low cost adsorbents used for dye removal, includes fruit waste of Prosopisn juliflora, sawdust, waste orange peel, banana pith and maze cobs. The ability of coconut bunch waste, an agricultural waste available in large 
quantity in Malaysia, to remove basic dye (methylene blue) from aqueous solution by adsorption was studied ${ }^{(5)}$. A batch sorption system using tree fern as biosorbent was investigated to remove Basic Red 13 from aqueous solutions ${ }^{(6)}$. Papaya seed (PS) was modified using chemically esterification of carboxyl group to improve performance in adsorption capacity for removal of cationic and anionic dye from aqueous solution ${ }^{(7)}$. The feasibility of quartenised sugar cane bagasse as an adsorbent for the removal of a cationic dye and an anionic dye from single and binary dye solutions was investigated ${ }^{(8)}$. On the other hand, the chemical modification of Ficus carica fiber was done with acrylic acid using ceric ammonium nitrate as initiator to change the surface morphology of the natural fibers for the improvement of interfacial adhesion between matrix and fibers to remove a hazardous methyl orange dye from aqueous system ${ }^{(9)}$. Activated carbon prepared from a sadiracted (neem) Seed Hull was used for removal of Rhodamine-B dye from aqueous solution ${ }^{(10)}$. Sawdust possesses porous structures consisting of various cell walls, which are mainly composed of biopolymers, i.e., carbohydrate polymers of cellulose and hemicelluloses and phenolic polymers of lignin. The cellular structure of sawdust endows it with high strength-to weight ratio. Because of this, some high-quality sawdust can be used as structural materials, besides, as the most abundant functional group in sawdust cell walls is the hydroxyl group ${ }^{(11)}$. Many efforts have been made to investigate the use of various low cost organic adsorbents, so the aim of the present study was to prepare natural adsorbent such as starch, sawdust and orange peel by grafting with acrylic acid (30\%OWS) and potassium bromate/thiourea (6mmole/100g substrate) as redox system to use it as a removal of C.I. Basic Blue 41 , from the effluent solution at temperature $30^{\circ} \mathrm{C}$.

\section{Experimantal}

Materials and methods

C.I. Basic Blue 41 (BB 41) was supplied from Dongwu Dyestuff Co. Ltd. (China). Molecular Formula: $\mathrm{C}_{20} \mathrm{H}_{26} \mathrm{~N}_{4} \mathrm{O}_{6} \mathrm{~S}_{2} / \mathrm{C}_{21} \mathrm{H}_{27} \mathrm{ClN}_{4} \mathrm{O}_{3} \mathrm{~S}$. Molecular Weight: 482.57/450.98 .Cationic dyes are more toxic than anionic dyes and the structure is shown in Fig. $1^{(12)}$.<smiles>CCN(CCO)c1ccc(N=Nc2sc3cc(OC)ccc3[n+]2C)cc1</smiles>

Fig. 1. Molecular structure of C.I. Basic Blue 41 (BB 41). 
Egyptian native maize starch supplied by the Egyptian Starch and Glucose Manufacturing Company, Cairo Egypt, sawdust collected from a local sawmill and orange peels. Acrylic acid, thiourea, potassium bromated, sodium hydroxide and sulfuric acid were all laboratory grade reagents.

\section{Preparation and characterization of adsorbent}

Preparation of grafted adsorbent

Orange peel and sawdust are washed and grind, $50 \mathrm{~g}$ of (starch, sawdust and orange peel) was put into glass vessel containing $60 \mathrm{ml}$ distilled water followed by gradual addition of alkali solution with concentration of $25 \mathrm{mmole} / 100 \mathrm{~g}$ substrate. The reaction vessel was then placed in a thermostatic water bath at $50^{\circ} \mathrm{C}$ for $30 \mathrm{~min}$ under mechanical stirring; the $\mathrm{pH}$ of the reaction medium was turned to the neutral by addition of dilute sulfuric acid. This was followed by subsequent addition of potassium bromated solution ( $6 \mathrm{~m} . \mathrm{mole} / 100 \mathrm{~g}$ substrate), acrylic acid 30\% (OWS) and thiourea (6m.mole/100g substrate). The whole course of grafting was carried out under constant stirring, temperature $50^{\circ} \mathrm{C}$ for 1 hr at liquor ratio $1: 2.5$.

\section{Measurements}

Infrared spectral analysis

Using (FT/IR-4100, Jasco, Japan) spectrometer, the structure and bond formation of the samples were confirmed. All spectra were recorded in the range (4000-400 $\mathrm{cm}^{-1}$ ), the number of scans was 32, and the resolution was $4 \mathrm{~cm}^{-1}$ and scan speed $2 \mathrm{~mm} / \mathrm{s}$. The $\mathrm{KBr}$ technique was used.

\section{Adsorption studies of C.I. Basic Blue 41 (BB 41)}

To assess the adsorption capacity of the prepared resins for removing C.I. Basic Blue 41 (BB 41) as shown in Fig. 1, the batch experiments were undertaken at the optimum $\mathrm{pH} 9$ and room temperature at $30^{\circ} \mathrm{C}$. A dye stock solution of $1000 \mathrm{mg} / \mathrm{L}$ was prepared by dissolving $1 \mathrm{~g}$ in $1 \mathrm{~L}$ distilled water for subsequent adsorption experiment. Initial concentrations from 50 to $200 \mathrm{mg} / \mathrm{L}$ of the dye were prepared by serial dilution of the stock solution. The equilibrium studies were performed by shaking $100 \mathrm{ml}$ of known initial concentrations of a dye with $0.1 \mathrm{~g}$ of each resin in $250 \mathrm{ml}$ conical flaks for $4 \mathrm{hr}$.

The effect of initial solution $\mathrm{pH}$ value ranging from 2 to 11 on the removal of Basic Blue 41 (BB 41) was studied by mixing $100 \mathrm{ml}$ of $100 \mathrm{mg} / \mathrm{L}$ dye solution with $0.1 \mathrm{~g}$ of adsorbent sample in various flasks of different $\mathrm{pH}$ values at $30^{\circ} \mathrm{C}$. The required $\mathrm{pH}$ value was adjusted by drop-wise addition of $0.1 \mathrm{M}$ of $\mathrm{NaOH}$ or $\mathrm{HCl}$ solution and recorded using $\mathrm{pH}$ meter. The flasks tested $\mathrm{pH}$ solutions were then covered with rubber caps and placed on a shaker at a fixed agitation speed of $200 \mathrm{rpm}$ for $4 \mathrm{hr}$. In addition the effect of resin dose was studied by conducting $0.25,0.5,1$ and 2 g per $100 \mathrm{ml}$ of $100 \mathrm{mg} / \mathrm{L}$ dye solution. The kinetic studies of basic blue dye 41 adsorbed by the herby resins were investigated by withdrawing aliquots of the solution containing $100 \mathrm{mg} / \mathrm{L}$ dye $(0.1 \mathrm{~g}$ adsorbent/100 
$\mathrm{ml}$ ) after desired contact time (0-240 $\mathrm{min})$ and then measured the absorbance of residual concentration of dye studied.

The concentrations of the dye before and after adsorption were estimated by using a Janway 6405 UV-VIS spectrophotometer, U.K., at a maximum wavelength of $480 \mathrm{~nm}$. The amounts of the adsorbed dye at equilibrium $\left(q_{e}\right.$, $\mathrm{mg} / \mathrm{g})$ and at time $t\left(q_{t}, \mathrm{mg} / \mathrm{g}\right)$ were calculated using equations 1 and 2 as follows:

$$
\begin{aligned}
& q_{e}=\frac{\left(C_{0}-C_{e}\right)}{\mathrm{m}} V \\
& q_{t}=\frac{\left(C_{0}-C_{t}\right)}{\mathrm{m}} V
\end{aligned}
$$

where $C_{0}, C_{e}$, and $C_{t}$ are the liquid-phase concentrations $(\mathrm{mg} / \mathrm{L})$ of dye at initial, equilibrium and time $t$, respectively. $V$ is the volume of solution (L) and $m$ is the mass of dried resins (g). In order to assess the reproducibility and error of the experimental results, all the absorbance measurements were performed in triplicate runs. It was found that the relative standard deviations are about $\pm 3 \%$.

\section{Results and Discussion}

\section{Investigation of principal surface groups by FTIR}

Figure 2 shows the assigned of the main components from native starch and grafted starch and starch adsorbed dye at equilibrium and differences between them can be detected by FTIR. A strong broad band of $\mathrm{OH}$ stretching vibration at $3431 \mathrm{~cm}^{-1}$ its intensity decreased in grafted starch. It is evidenced an increase in the intensity band of $\mathrm{OH}$ in starch adsorbed dye at equilibrium and became brooded and shifted to higher wavenumber at $3447 \mathrm{~cm}^{-1}$. The carbonyl absorption band at $1732 \mathrm{~cm}^{-1}(\mathrm{C}=\mathrm{O})$ is increased in grafted starch than that native and adsorbed starch. The absorption peak at $2928 \mathrm{~cm}^{-1}$ was attributed to the $\mathrm{C}-\mathrm{H}$ stretching vibration of carbohydrates; the peak at $1732 \mathrm{~cm}^{-1}$ corresponded to the $\mathrm{C}=\mathrm{O}$ stretching vibration, indicating the presence of an acetyl group in starch. The absorption peak at $1649 \mathrm{~cm}^{-1}$ corresponded to the $\mathrm{C}=\mathrm{O}$ stretching vibration within $-\mathrm{CHO}$, the peaks at 1460 and $1425 \mathrm{~cm}^{-1}$ were attributed to the $\mathrm{C}-\mathrm{O}-\mathrm{C}$ plane bending vibration and the peak at $1380 \mathrm{~cm}^{-1}$ was ascribed to the $\mathrm{O}-\mathrm{H}$ bending vibration. In addition, starch adsorbed dye has new band at $1581 \mathrm{~cm}^{-1}$. The band at $1158 \mathrm{~cm}^{-1}$ was attributed to the asymmetric $\mathrm{C}-\mathrm{O}-\mathrm{C}$ stretching vibration, indicating the presence of $-\mathrm{O}-\mathrm{CH}_{3}$, and in the region between 1200 and $900 \mathrm{~cm}^{-1}$, several strong absorption peaks assigned to the $\mathrm{C}-\mathrm{C}$ and $\mathrm{C}-\mathrm{O}$ stretching modes appeared ${ }^{(13)}$.

Egypt. J. Chem. 58, No. 2 (2015) 


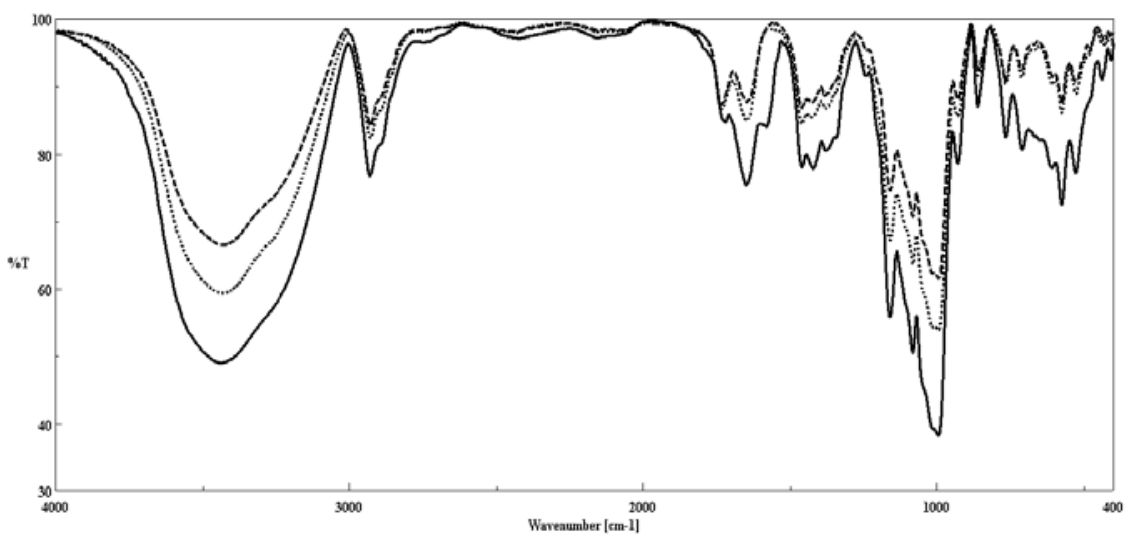

Fig. 2. FTIR spectra of investigated adsorbents .

\section{.... native starch - ------ grafted starch — starch adsorbed dye}

Figure 3 shows the FTIR spectra of sawdust, grafted sawdust and sawdust adsorbed dye at equilibrium. Clear differences can be detected in the infrared spectra. A decrease in the intensity of the $\mathrm{O}-\mathrm{H}$ band at $3442 \mathrm{~cm}^{-1}$ was observed in the grafted sawdust and then shifted to a lower wavenumber at 3435 $\mathrm{cm}^{-1}$, and became sharp and increased its intensity in sawdust adsorbed dye at equilibrium. On the other hand, the intensity of carbonyl absorption band at 1735 $\mathrm{cm}^{-1}(\mathrm{C}=\mathrm{O})$ increased in sawdust after grafted than another one ${ }^{(14)}$.

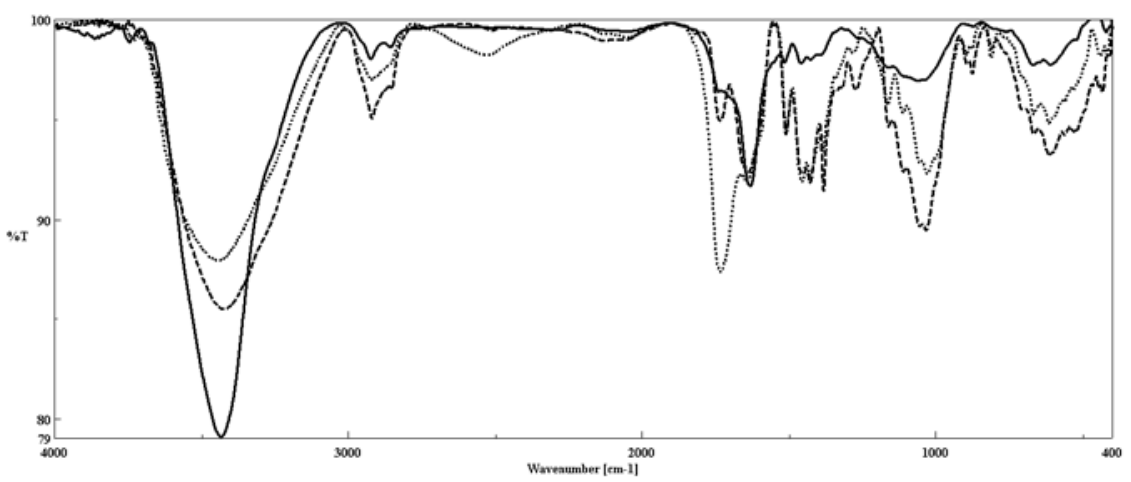

Fig. 3. FTIR spectra of investigated adsorbents .

----- sawdust ....... grafted sawdust - sawdust adsorbed dye

The FTIR spectrum of the orange peel is shown in Fig. 4, the broad and intense absorption peaks around $3423 \mathrm{~cm}^{-1}$ are indicative of the absorption of water molecules, resulting from the $\mathrm{O}-\mathrm{H}$ stretching mode of hydroxyl groups which is a characteristic of adsorbed water. Generally, the increase in $\mathrm{OH}$ and carboxyl groups $(-\mathrm{COOH})$ follows the order: orange peel $>$ grafted orange $>$ orange adsorbed dye at equilibrium, respectively ${ }^{(15-20)}$. 


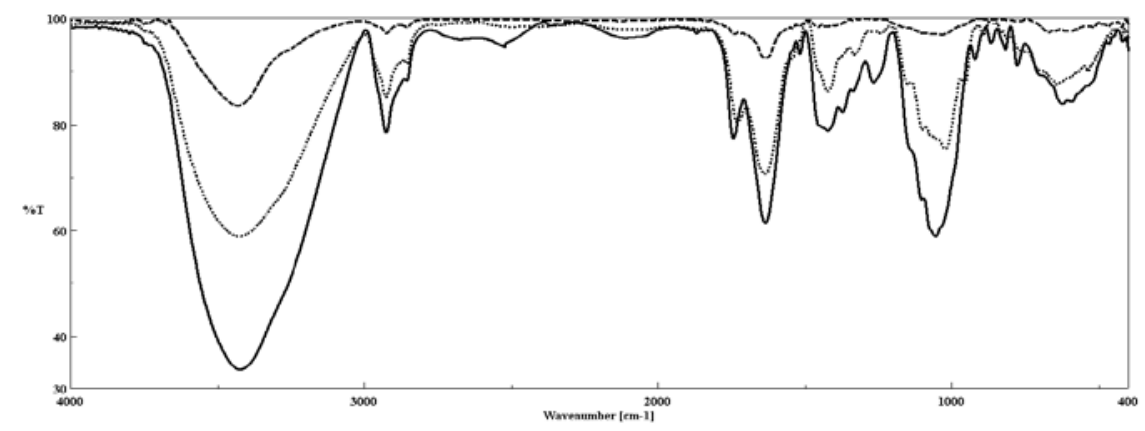

Fig. 4. FTIR spectra of investigated adsorbents .

orange $\ldots . .$. .. grafted orange orange adsorbed dye

Effect of $p H$

The change in $\mathrm{pH}$ of dye solution affects the surface charges of adsorbents which lead to variation in the degree of ionization of the adsorptive molecule and hence the surface properties of adsorbents. Adsorption of various anionic and cationic species on such adsorbents has been explained on the basis of the competitive adsorption of $\mathrm{H}^{+}$and $\mathrm{OH}^{-}$ions with the adsorbate ${ }^{(21)}$. It is a common observation that the surface adsorbs anions favorably at lower $\mathrm{pH}$ due to the presence of $\mathrm{H}^{+}$ions whereas; the surface is active for the adsorption of cations at higher $\mathrm{pH}$ due to adsorption of $\mathrm{OH}^{-}$ions ${ }^{(22)}$. Figure 5 shows the adsorbed amounts of dye by grafted natural adsorbents under different $\mathrm{pH}$ of dye solution. A lower adsorbed amount was found at $\mathrm{pH} 2$ (acidic medium) while the higher amount occurred at $\mathrm{pH} 9$ (basic media), attaining a constant removal at $\mathrm{pH} 11$. This trend may be ascribed to the occurrence of electrostatic interaction resulting in the increase in negative surface charges of the adsorbent and the basic blue dye adsorbate. Also, it was found that the sawdust resin showed the highest adsorption of dye at $\mathrm{pH} 9$.

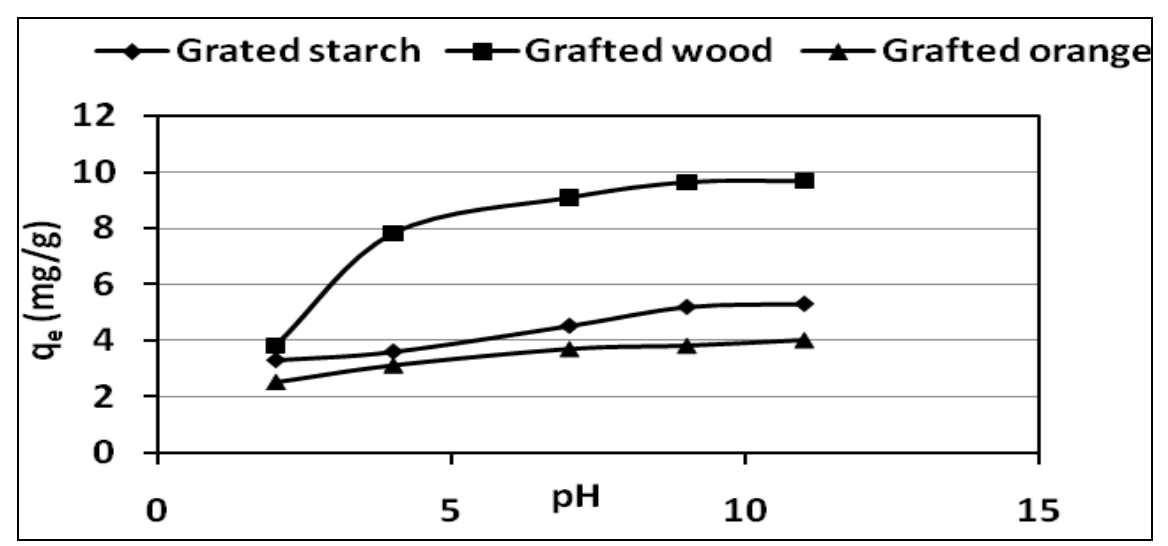

Fig. 5. Influence of pH on removal of C.I. Basic Blue 41 (BB 41) . Conditions: sorbent dosage $0.1 \mathrm{~g} / 100 \mathrm{ml}$, temperature $30^{\circ} \mathrm{C}, 200 \mathrm{rpm}$ for $4 \mathrm{hr}$

Egypt. J. Chem. 58, No. 2 (2015) 


\section{Effect of resin dose}

The amount of adsorbent represents an important parameter due to its strong effect on the capacity of an adsorbent at a given initial concentration of the adsorbate $(100 \mathrm{mg} / \mathrm{L})$. Figure 6 expresses the effect of adsorbent dosage on the removal of basic blue dye. This figure reveals that the adsorbed amount was decreased with increasing the grafted natural adsorbents dose from 0.25 up to 2 $\mathrm{g} / 100 \mathrm{ml}$. Thus the higher adsorbed amount of dye was found with $0.25 \mathrm{~g}$ resin/100ml dye solution, although the other adsorption experiments were carried out with $1 \mathrm{~g}$ resin/100 $\mathrm{ml}$ dye solution. The decrease in amount of dye adsorbed, $\mathrm{q}_{\mathrm{e}}(\mathrm{mg} / \mathrm{g}$ ) with increasing adsorbent mass, is due to the concentration gradient between solute concentration in the solution and the solute concentration in the surface of the adsorbent ${ }^{(23)}$.

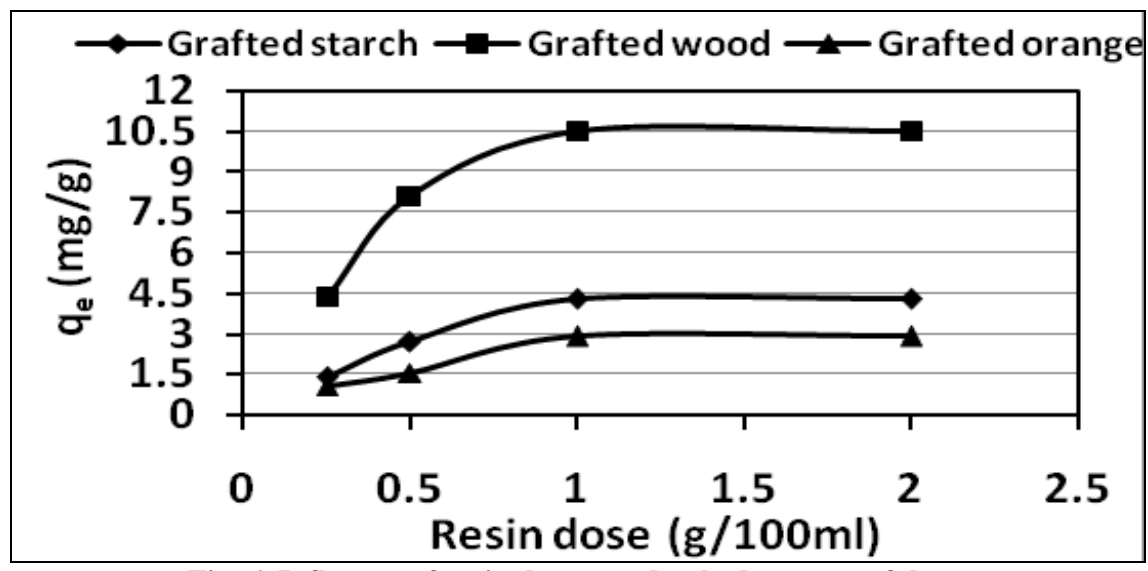

Fig. 6. Influence of resin dose on adsorbed amount of dye .

Conditions: sorbent dosage $0.1 \mathrm{~g} / 100 \mathrm{ml}$, temperature $30^{\circ} \mathrm{C}, 200 \mathrm{rpm}$ for $4 \mathrm{hr}$, ph 9

Effect of contact time

The effect of contact time on the adsorption of basic blue dye was investigated at different initial dye concentration onto pine cone adsorbent, and results are presented in Fig. 7. It was also found that the amount of adsorption, i.e. milligrams of adsorbate per gram of adsorbent, increases with increasing contact time at an initial dye concentration of $100 \mathrm{mg} / \mathrm{L}$, and equilibrium is attained within $120 \mathrm{~min}$. The removal of dye by adsorption on grafted natural adsorbents is very fast at the initial period of contact but slowed down with time. This kinetic experiment clearly showed that the adsorption of C.I. Basic Blue 41 (BB 41) dye on grafted natural adsorbents is a more or less two step process: a very rapid adsorption of dye to the external surface followed by possible slow intraparticle diffusion in the interior of the adsorbent with increasing in the time. Generally, the rapid kinetics have significant practical importance, as it facilitates smaller reactor volumes, ensuring high efficiency and economy. 


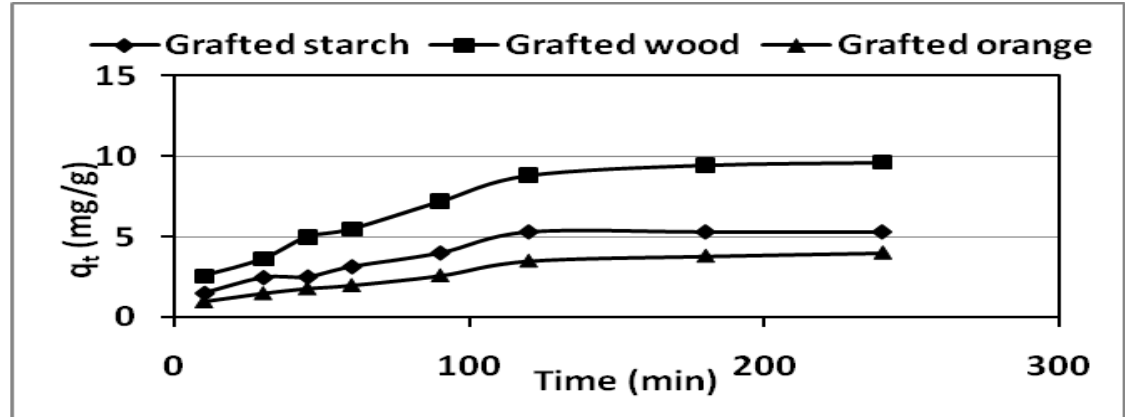

Fig. 7. Influence of contact time on the adsorption of dye .

Conditions: time 0-120 min., pH 9, temperature $30^{\circ} \mathrm{C}, 200 \mathrm{rpm}$ for $4 \mathrm{hr}$

Adsorption isotherm models

The Langmuir and Freundlich isotherm models were employed for fitting the experimental data. The Langmuir model describes the assumption that the surface of the sorbent is totally homogeneous, whereas the Freundlich isotherm is suitable for a highly heterogeneous surface.

The linear form of the Langmuir isotherms:

$$
c_{e} / q_{e}=\frac{1}{k_{L} q_{m}}+\frac{1}{q_{m}} c_{e}
$$

where $\mathrm{q}_{\mathrm{m}}$ is the maximum amount adsorbed assumed to be the monolayer adsorption capacity, both expressed in (mg. $\mathrm{g}^{-1}$ ) and $K_{L}$ is the Langmuir constant (mg. $\left.L^{-1}\right)$ relating to the free energy of sorption as expressed $\left(K_{L} \alpha \mathrm{e}^{-\Delta \mathrm{G} / \mathrm{RT}}\right)$.

Thus the free energy of adsorption, $\Delta G\left(\mathrm{~kJ} \mathrm{~mol}^{-1}\right)$ can also be evaluated from the parameter $K_{L}$ according to the expression; $\Delta G=-R T \ln K_{L}$. The linear form of the Freundlich equation is given as:

$$
\operatorname{Ln} q_{e}=\ln K_{F}+1 / n \ln C_{e}
$$

where $K_{F}$ is the Freundlich constant related to the adsorption capacity, in which $1 / n$ is a constant related to the adsorption strength, i.e., the adsorbent- adsorbate interaction. In addition the essential features of Langmuir adsorption isotherm can be expressed in terms of a dimensionless separation factor $\left(R_{\mathrm{L}}\right)$, which is given by equation:

$$
R_{L}=\frac{1}{1+C_{0} K_{L}}
$$


where $C_{0}$ is the initial metal ions concentration $(\mathrm{mg} / \mathrm{l})$. The $R_{\mathrm{L}}$ value indicates the shape of the isotherm to be irreversible $\left(R_{\mathrm{L}}=0\right)$, favorable $\left(0<R_{\mathrm{L}}<1\right)$, linear $\left(R_{\mathrm{L}}\right.$ $=1$ ) or unfavorable isotherm $\left(R_{\mathrm{L}}>1\right)$. Also, $R_{\mathrm{L}}$ values are represented in Table 1 , which confirmed that the prepared carbons are highly favorable for adsorption of basic dye from wastewater under the reported conditions used in

this study. Moreover, the negative value of Gibbs free energy $\left(\Delta G^{0}=-22.5\right.$ to $29.4 \mathrm{~kJ} \mathrm{~mol}^{-1}$ ) confirms the feasibility and spontaneous nature of the adsorption of this dye onto the tested resins. Parameters of Langmuir and Freundlich models and their corresponding regression coefficients $\left(r^{2}\right)$ are listed in Table 1. Figure 8 shows the adsorption isotherms of a Basic Blue 41 (BB 41) onto the grafted resins, representing L-type of adsorption isotherm. In the range of tested initial concentrations, Langmuir $\left(r^{2}=0.959-0.999\right)$ and Freundlich models $\left(r^{2}=0.940\right.$ 0.972 ) fit the adsorption data well. The maximum adsorption capacity values for dye adsorbed onto the tested grafted natural adsorbents; Starch, Sawdust and Orange were $7.85,19.2$ and $4.90 \mathrm{mg}^{-1} \mathrm{~g}^{-1}$, respectively (Table 1).

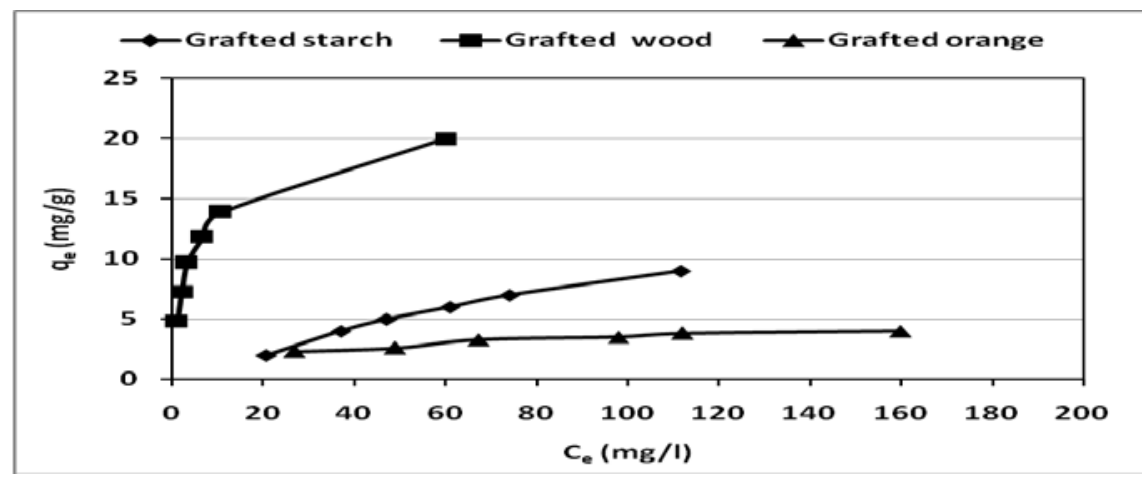

Fig. 8. Adsorption isotherms of BB41 dye onto the adsorbent grafted natural adsorbents .

TABLE 1. Parameters calculated from Langmuir and Freundlich isotherm models for adsorption of basic blue dye onto the prepared grafted natural adsorbents.

\begin{tabular}{|c|c|c|c|}
\hline Equilibrium models & \multicolumn{3}{|c|}{ Grafted natural adsorbents } \\
\hline Langmuir & Grafted Starch & Grafted sawdust & Grafted Orange \\
\cline { 2 - 4 }$q_{m}\left(\mathrm{mg}^{-1}\right)^{-1}$ & 7.58 & 19.2 & \\
$K_{L}\left(\mathrm{~L} \cdot \mathrm{mg}^{-1}\right)$ & 0.0176 & 0.2756 & 4.90 \\
$R_{L}$ & 0.811 & 0.411 & 0.0281 \\
$\Delta \mathrm{G}^{0}\left(\mathrm{~kJ} . \mathrm{mol}^{-1}\right)$ & -22.5 & -29.4 & 0.637 \\
$r^{2}$ & 0.959 & 0.999 & -23.7 \\
& & & 0.990 \\
\hline & 0.212 & 5.31 & 1.30 \\
Freundlich & 0.802 & 0.377 & 0.330 \\
$K_{F}\left(\mathrm{mg}^{-1} \mathrm{~g}^{-1}(\mathrm{~L} / \mathrm{mg})^{-1 / n}\right)$ & 0.972 & 0.940 & 0.953 \\
$1 / n$ & & & \\
$r^{2}$ & & & \\
\hline
\end{tabular}


Kinetics of adsorption

The adsorption kinetic process is largely dependent on the physical and/or chemical characteristics of both the adsorbent and adsorbate ${ }^{(24-27)}$. Figure 9 shows the controlling mechanism in the adsorption of the basic blue 41 (BB41) with initial concentration of $100 \mathrm{mg} / \mathrm{L}$ at $30^{\circ} \mathrm{C}$ examined using various kinetic models such as pseudo-first order, pseudo-second order and Elovich models in order to determine whether the process is such as mass transfer and/or chemical reaction were evolved:

$$
\begin{aligned}
& \log \left(q_{e}-q_{t}\right)=\log q_{e}-\frac{k_{1} t}{2.303} \\
& \frac{t}{q_{t}}=\frac{1}{k_{2} q_{e}{ }^{2}}+\frac{t}{q_{e}}
\end{aligned}
$$

where $q_{e}$ and $q_{t}$ are the amounts of solute adsorbed at equilibrium and at a time $\mathrm{mg} / \mathrm{g}$, respectively, $k_{1}$ is the pseudo-first order sorption rate constant $\left(\mathrm{min}^{-1}\right)$, and $k_{2}$ is the pseudo-second order sorption rate constant $\left(\mathrm{g} . \mathrm{mg}^{-1} \mathrm{~min}^{-1}\right)$. In a further attempt to study the nature of sorption, another equation, namely, Elovich equation, normally applicable to chemisorption on energetically heterogeneous solid surface, and given by:

$$
q_{t}=\beta \ln (\alpha \beta)+\beta \ln t
$$

where $\alpha$ and $\beta$, respectively the initial adsorption rate $\left(\mathrm{mg} \cdot \mathrm{g}^{-1} \mathrm{~min}^{-1}\right.$ ) and the desorption coefficients (g. $\mathrm{mg}^{-1}$ ), respectively. These can be computed from plots of $q_{\mathbf{t}}$ versus $\ln t$. The calculated values of model parameters are given in Table 2. The regression coefficients of the linear form of model $\left(r^{2}\right)$, which are a measure of goodness of fit in Table 2, indicate that the pseudo-first-order model $\left(r^{2}=0.962-0.987\right)$ more frequently describes the adsorption data with the pseudo-second-order model $\left(r^{2}=0.919-0.972\right)$. Calculated $q_{e}$ values from pseudo-first order showed good consistency with the detected values in experiment (5.3, 9.8 and $4.5 \mathrm{mg} / \mathrm{g}$, respectively).

The values of $\alpha$ and $\beta$ and the corresponding $R^{2}$ are listed in Table 2 . Evidently the Elovich plots are non-linear with values of $R^{2}=0.897$ to 0.939 . The initial rate of adsorption $(\alpha)$ of sawdust resin was higher than those of other resins. On the other hand, the corresponding desorption rate coefficient values $(\beta)$ are lower than $\alpha$ values. This confirms that the adsorption of the dye on the resin was held at energetically uniform sites, and perhaps at chemically different sites.

Egypt. J. Chem. 58, No. 2 (2015) 


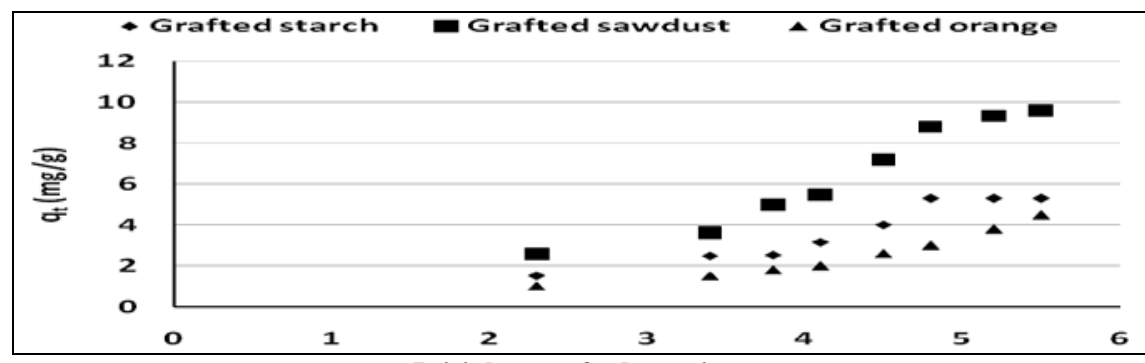

Initial rate of adsorption

Fig. 9. Elovich kinetic plots for the adsorption of dye on the adsorbents (adsorbent dose $=1 \mathrm{~g} ; \mathrm{pH}=9$; Temp., $=30^{\circ} \mathrm{C}$; contact time $=4 \mathrm{hr}$ ).

TABLE 2. Kinetic modles parameters for the adsorption of basic dye onto the prepared grafted natural adsorbents.

\begin{tabular}{|l|c|c|c|c|c|c|c|c|c|c|}
\hline \multirow{2}{*}{ Samples } & \multicolumn{2}{|c|}{ First order kinetic } & \multicolumn{4}{c|}{ Second order kinetic } & \multicolumn{3}{c|}{ Elovich model } \\
\cline { 2 - 10 } & $\begin{array}{c}\mathbf{q}_{\mathbf{e}} \\
(\mathbf{m g} / \mathbf{g})\end{array}$ & $\begin{array}{c}\mathbf{k}_{\mathbf{1}} \\
\left(\mathbf{m i n}^{-1}\right)\end{array}$ & $\mathbf{r}^{2}$ & $\begin{array}{c}\mathbf{q}_{\mathbf{e}} \\
(\mathbf{m g} / \mathbf{g})\end{array}$ & $\begin{array}{c}\mathbf{k}_{2} \\
(\mathbf{g} / \mathbf{m g m i n})\end{array}$ & $\begin{array}{c}\mathbf{h} \\
(\mathbf{m g} / \mathbf{g} \cdot \mathbf{m i n})\end{array}$ & $\mathbf{r}^{2}$ & $\boldsymbol{\alpha}$ & $\boldsymbol{\beta}$ & $\mathbf{r}^{2}$ \\
\hline $\begin{array}{l}\text { Grafted } \\
\text { Starch }\end{array}$ & 4.44 & 0.0115 & 0.964 & 6.62 & $2.92 \times 10^{-3}$ & 0.128 & 0.964 & $1.05 \times 10^{-3}$ & 1.374 & 0.907 \\
\hline $\begin{array}{l}\text { Grafted } \\
\text { sawdust }\end{array}$ & 10.9 & 0.0184 & 0.987 & 12.0 & $1.46 \times 10^{-3}$ & 0.210 & 0.972 & $4.90 \times 10^{-3}$ & 2.496 & 0.939 \\
\hline $\begin{array}{l}\text { Grafted } \\
\text { orange }\end{array}$ & 4.13 & 0.0138 & 0.962 & 5.81 & $1.88 \times 10^{-3}$ & 0.063 & 0.919 & $1.76 \times 10^{-11}$ & 1.086 & 0.897 \\
\hline
\end{tabular}

\section{Conclusions}

In this work, grafted natural adsorbents such as starch, orange peel and sawdust (collected from a local sawmill) were grafted with acrylic acid and potassium bromated/thiourea as redox system after alkali treatment to remove basic blue dye 41 (BB41) from the aqueous solution by adsorption. Characterization of the natural adsorbents by the FTIR spectra was performed. The carbonyl absorption band at $1732 \mathrm{~cm}^{-1}(\mathrm{C}=\mathrm{O})$ is increased in grafted starch more than that native and adsorbed starch, and becomes sharp and an increase in its intensity in the sawdust adsorbed dye was obtained. The $\mathrm{OH}$ group is increased in orange peel grafted but carboxylic group is decreased. This result is different from the FTIR spectra of starch and sawdust and compatible with the adsorption studies of Basic Blue 41 Dye. Overall, the carboxylic groups are increased after grafting of starch and sawdust, and hence the active adsorption sites available for the adsorption of Basic Blue 41 dyes. Batch adsorption results showed that the removal of basic dye from aqueous solution was investigated in the following order; sawdust $>$ starch >orange. Also, these results were analyzed using two principal isotherm models, Langmuir and Freundlich. It was found that the equilibrium isotherms were well described by the Langmuir equation, giving a maximum adsorption capacity of $19.2 \mathrm{mg} / \mathrm{g}$ by sawdust at $30^{\circ} \mathrm{C}$. Furthermore, the adsorption kinetics can be well represented by the pseudo-second-order model equation ${ }^{(24-27)}$. 


\section{Reference}

1. Namasivayam, C. and Kanchana, N., Removal of Congo red from aqueous solution by waste banana pith. Pertanika Journal of Science Technology, 1(1), 33-42 (1993).

2. Sarioglu, M. and Atay, U., Removal of methylene blue by using biosolid. Global Nest Journal, 8 (2), 113-120 (2006).

3. Muyibi, S.A. and Alfugara, A.M.S., Treatment of surface water with Moringa oleifera seed extract and Alum - A comparative study using A pilot scale water treatment plant. International Journal of Environmental Studies, 60 (6), 617- 626 (2003)

4. Elisangela, F., Matthew, J.G., Jonas, A.R.P., Felix, G.R.R. and Lucia, R.D., Decolorization and biodegradation of reactive sulfonated azo dyes by a newly isolated Brevibacterium sp. strain VN-15. A Springer Open Journal, 37 (1) , 1-10 (2012)

5. Hameed, B.H. Mahmoud, D.K and Ahmad, A.L., Equilibrium modeling and kinetic studies on the adsorption of basic dye by a low-cost adsorbent: Coconut (Cocos nucifera) bunch waste. Journal of Hazardous Materials, 158, 65-72 (2008).

6. Yuh, S.H., Tzu, H.C. and Yu, M.H., Removal of basic dye from aqueous solution using tree fern as a biosorbent. Process Biochemistry, 40, 119-124 (2005)

7. Nasuha, N., Zurainan, H.Z., Maarof, H.I., Zubir, N.A. and Amri, N., Effect of cationic and anionic dye adsorption from aqueous solution by using chemically modified papaya seed. International Conference on Environment Science and Engineering, 8, 50 -55 (2011).

8. Wong, S.Y., Tan, Y.P., Abdullah, A.H. and Ong, S.T., The removal of basic and reactive dyes using quartenised sugar cane bagasse. Journal of Physical Science, 20 (1), 59-74 (2009)

9. Vinod, K.G., Deepak, P., Shikha, S., Shilpi, A. and Prerna S., Remediation and recovery of methyl orange from aqueous solution onto acrylic acid grafted Ficus carica fiber: Isotherms, kinetics and thermodynamics. Journal of Molecular Liquids, 177, 325-334 (2013)

10. Porselv, E. and Krishamoorthy, P., Adsorptive removal of rhodamine -by agriculture waste. Oriental Journal of Chemistry, 29 (2), 719- 723 (2013).

11. Alfred, J., "Sawdust Technology Chemical Aspects”, American Chemical Society, Washington, DC, p.115-140 (1977).

12. Nandi, B.K., Goswami, A. and Purkait, M.K., Adsorption characteristics of brilliant green dye on Kaolin. Journal of Hazardous Materials, 161, 387-395 (2009).

13. Bellon-Maurel, V., Vallat, C. and Goffinet, D., Quantitative analysis of individual sugars during starch hydrolysis by FT-IR/ATR spectrometry. Part I: Multivariate

Egypt. J. Chem. 58, No. 2 (2015) 
calibration study-repeatability and reproducibility. Appl. Spectrosc. 49, 556-562 (1995).

14. BODÎRLĂU, R. and TEACĂ. C.A., Fourier transform infrared spectroscopy and thermal analysis of lignocelluose fillers treated with organic anhydrides, Rom. Journ. Phys. 54, 93-104 (2009).

15. Al-Qodah, Z. and Shawabkah, R., Production and characterization of granular activated carbon from activated sludge. Braz. J. Chem. Eng. 26 (1), 127 (2009)

16. Guibavd, G., Tixier, N., Bouju, A. and Baudu, M., Relation between extracellular polymer's composition and its ability to complex $\mathrm{Cd}, \mathrm{Cu}$ and $\mathrm{Pb}$. Chemosphere, 52, 17011710 (2003).

17. Khaled, A., El Nemr, A., El-Sikaily, A. and Abdelwahab, O., Removal of direct N Blue-106 from artificial textile dye effluent using activated carbon from orange peel: Adsorption isotherm and kinetic studies. Hazard. Mater. 165, 100 (2009) .

18. Farinella, N.V., Matos, G.D. and Arruda, M.A.Z., Grape bagasse as a potential biosorbent of metals in effluent treatments. Bio. Tec. 98, 1940-1946 (2007)

19. Guibavd, G., Tixier, N., Bouju, A. and Baudu, M., Relation between extracellular polymer's composition and its ability to complex $\mathrm{Cd}, \mathrm{Cu}$ and $\mathrm{Pb}$. Chemosphere, 52, 1701-1710 (2003).

20. Sha, L., Xue-yi, G., Ning-chuan, F. and Qing-hua T., Effective removal of heavy metals from aqueous solutions by orange peel xanthate. Transactions of Nonferrous Metals, Society of China. 20, 187-191(2010)

21. Indra, M. D.,Vimal, C.S. and Nitin A.K., Removal of orange-G and methyl violet dyes by adsorption onto bagasse fly ash-kinetic study and equilibrium isotherm analyses. Dyes and Pigments, 69, 210 - 223 (2006).

22. Banat, F., Asheh, A.A. and Makhadmeh, L., Utilization of raw and activated date pits for the removal of phenol from aqueous solutions . Chem. Eng. Techno, 27 (1), 80-86 (2004).

23. Vadivelan, V. and Kumar, K.V., Equilibrium, kinetics, mechanism \& process design for the sorption of methylene blue onto rice husk. Journal of Colloid and Interface Science, 286, 90-100 ( 2005).

24. Ho, Y.S., Review of second- order models for adsorption systems. J. Hazardous Materials, 136 (3), 681- 689 (2006)

25. Webeer, W.J. and Morris, J.C., Kinetics of adsorption of carbon from solution. $J$. the Sanitary Engineering Division-ASCE., 89 (2), 31-59 (1963). 
26. Fathy, N.A., Girgis, B.S., Khalil Laila, B. and Farah, J.Y., Utilization of cotton stalks- Biomass waste in the production of carbon adsorbents by $\mathrm{KOH}$ activation for removal of dye- contaminated water. Carbon Letters, 11 (3), 224- 234 (2010).

27. Fathy, N.A., El-Shafey, Ola I. and Khalil Laila, B., Effectiveness of alkali-acid treatment in enhancement the adsorption capacity for Rice straw: The removal of methylene blue dye. ISRN Physical Chem. 1,5 (2013) .

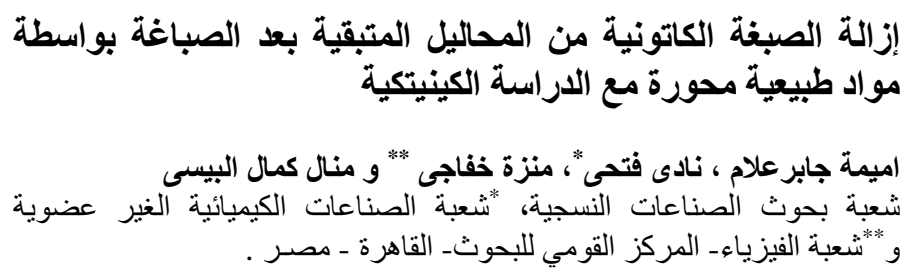

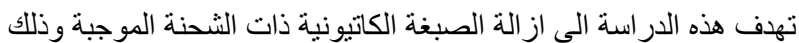

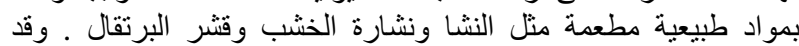

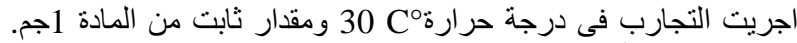

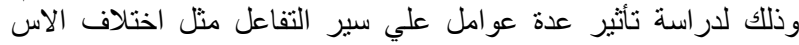

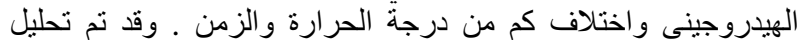

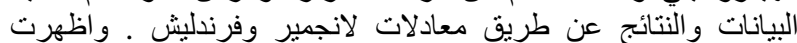

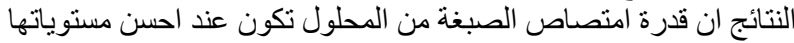

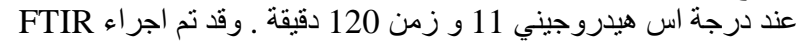

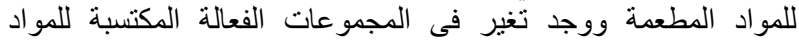

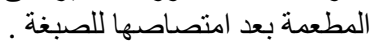

